1. BDS, FCPS

Assistant Professor Oral \&

Maxillofacial Surgery

Dental College-HITEC (IMS)-Taxilla

Cantt.

2. BDS, FCPS

Assistant Professor Oral \&

Maxillofacial Surgery

Sir Syed College of Medical

Sciences for Girls, Karachi.

3. BDS, FCPS

Senior Registrar Orthodontics

Shifa College of Dentistry.

4. BDS

Registrar Oral \& Maxillofacial

Surgery

Dental College-HITEC (IMS)-Taxilla Cantt.

5. BDS, MDS

Assistant Professor Orthodontic

Dental College-HITEC (IMS)-Taxilla

Cantt.

6. BDS, PhD

Assistant Professor Community Dentistry

School of Dentistry-SZABMU

Islamabad

Correspondence Address:

Dr. Maimoona Siddiq

Department of Oral \& Maxillofacial

Surgery

Dental College-HITEC (IMS)-Taxilla

Cantt.

the dentist007@hotmail.com

Article received on:

14/11/2020

Accepted for publication:

25/01/2021

\section{Root morphology of maxillary 1st premolar teeth in orthodontic extraction cases presenting in a tertiary care hospital: Taxilla Cantt.}

Maimoona Siddiq ${ }^{1}$, Junaid Shakeel ${ }^{2}$, Bushra Naeem $\mathrm{Khan}^{3}$, Syed Zuhair Mehdi $^{4}$, Shoaib Hameed ${ }^{5}$, Farooq Ahmad Chaudhary ${ }^{6}$

ABSTRACT... Objective: To observe pattern and variation of root morphology of maxillary 1st premolar teeth in orthodontic extraction cases among local population. Study Design: Prospective Observational study. Setting: Dental College-HITEC Institute of Medical SciencesTaxilla Cantt. Period: 1st January 2017 to 31st December 2019. Material \& Methods: A total of 160 patients and 320 maxillary 1st premolars were studied clinically for gross root morphology after orthodontic tooth extraction, variation of gross root morphology was studied among extracted teeth, frequency distribution was observed on basis of gender and both quadrants in each patient, a critical analysis is also made about variation of root morphology among various populations across the world. Result: Out of 160 patients, 49 were males and 111 were females. 151 patients had bilateral similar root morphology, out of 320 clinically examined teeth 206 had two roots, and 123 teeth had fused root morphology, 83 teeth had two bifurcated (separate) roots while 114 teeth were single rooted. Conclusion: Maxillary 1st premolar is unique in terms of wide variation in root morphology which is evident among various population studies. Two roots with fused root morphology is most prevalent in Pakistani population.

Key words: $\quad$ Atraumatic, Extraction Technique, Maxillary 1st Premolar, Orthodontic Tooth Extraction, Periotome, Root Morphology.

Article Citation: Siddiq M, Shakeel J, Khan BN, Mehdi SZ, Hameed S, Chaudhary FA. Root morphology of maxillary 1st premolar teeth in orthodontic extraction cases presenting in a tertiary care hospital: Taxilla Cantt. Professional Med J 2021; 28(7):1013-1017. https://doi.org/10.29309/TPMJ/2021.28.07.6209

\section{INTRODUCTION}

One of the first orthodontists to indicate permanent tooth extractions for correction of malocclusions was Charles Tweed, who found that only $20 \%$ of his clinical cases treated without extractions were successful. ${ }^{1}$ It is clearly evident that extractions are inevitable in most of orthodontic treatment cases.

Maxillary $1^{\text {st }}$ premolars are most common tooth to extract for orthodontic treatment purpose because of their position and compatible size with most types of discrepancies in cases that require the retraction of anterior teeth. ${ }^{1}$

Consistent coronal description of this tooth is well explained in literature, but variation in root morphology is evident among various populations, with a higher incidence, which makes this tooth quite distinctive. ${ }^{2}$
Its variation of root morphology has been a topic of interest, it has been studied among various Asian populations, like East-Asian (Chinese) ${ }^{3}$, South-Asian (Nepalese) ${ }^{4}$, South-East Asian (Singaporean) $^{5}$ and West-Asian (Saudia Arabia and Jordanian) ${ }^{6,7}$ along with Africans and Europeans. No study has yet been put forward among Pakistani population.

Roots may easily get fractured if early luxation is too vigorous. ${ }^{8}$ A maxillary universal forceps is typically used for these teeth to be extracted. Initially, the forceps is seated and pushed apically, Careful buccal-palatal movement, allowing time for the bone to expand under firm pressure, is repeated until the alveolar bone is expanded, the tooth is mobile, and the periodontal attachment loosened. ${ }^{9}$

Although an atraumatic extraction technique like 
use of physics forceps or periotomes can also be advocated. ${ }^{10}$

Gross root morphology of maxillary $1^{\text {st }}$ premolar and its variation among our local population should be clearly understood and appreciated by oral surgeons, who are extracting these teeth for orthodontic treatment and planning.

Rationale and Aim of this study is to assess root form of maxillary $1^{\text {st }}$ premolar tooth among our indigenous Pakistani population which will help oral surgeons to avoid any uneventful extraction scenario like root fracture which may lead to "surgical extraction", which is not desired when extraction is for orthodontic purpose.

A thorough knowledge of gross root morphology of local population and a careful extraction technique is thus required in view of its variable root morphology to employ an atraumatic extraction with avoidance of root break or bone loss with maximum socket preservation.

\section{METHODOLOGY}

The study design is prospective (descriptive), which is conducted at Oral \& Maxillofacial Surgery Department of Dental College-HITEC Institute of Medical Sciences. All the patients presented in Orthodontics Department of Dental CollegeHITEC Institute of Medical Sciences from $1^{\text {st }}$ January 2017 to $31^{\text {st }}$ December 2019 , which met with inclusion criteria are included in the study.

A total of 160 patients (males and females) were included and $160+160=320$ teeth were observed in terms of gross root morphology. Extraction was performed under local anesthesia, each patient had bilateral extraction from both right and left maxillary quadrant. Data was collected from Oral \& Maxillofacial Surgery Department, which included only the patients referred from Orthodontic Department of same hospital. All subjects of this study were candidates of maxillary $1^{\text {st }}$ premolar extraction bilaterally, between the ages of 12 years to 25 years. Patients who were not orthodontic treatment extraction cases, referred from other settings, extractions other than $1^{\text {st }}$ pre-molar maxilla, cleft lip \& palate, patients with syndrome condition, and teeth that were grossly carious are not included in this study. Informed consent was taken from each patient for inclusion in this study, every patient was well versed with rationale of extraction. Study was conducted after approval from ethical review board (ERB), held on $22^{\text {nd }}$ December 2016, with IRB letter number F.2/2020/ ERB/DC/HITEC-IMS.

Extracted maxillary $1^{\text {st }}$ premolars were divided into four groups according to root morphology

Group I: single rooted

Group II: two rooted (fused)

Group III: two rooted (separate)

Group IV: three rooted

These above mentioned groups were compared in terms of frequency distribution and percentage among both quadrants in each patient, on basis of right and left quadrant among all patients, gender distribution was also noted.

SPSS version 26 was used for statistical data analysis, descriptive analysis of variables (root morphology groups and gender distribution) is calculated, level of significance was kept as $P=0.05$. Chi-square test was applied to observe variation of root morphology among both genders.

\section{RESULTS}

A total of 160 patients were included in study and 320 teeth were examined for root morphology after extraction.

Out of 160 patients, 49 were male and 111 were females which is $30.6 \%$ and $69.4 \%$ respectively with mean age of 17.3 years (Table-I)

Table-Il explains Root morphology in Right quadrant, as $35.6 \%, 38.1 \%$ and $26.3 \%$ for group I (single root), group II (two roots-fused) and group III (two roots-separated) respectively.

Similarly Table-III explains Root morphology in Left quadrant, as $35.6 \%, 38.8 \%$ and $25.6 \%$ for group I (single root), group II (two roots-fused) and group III (two roots-separated) respectively. Table-IV explains percentage and frequency of 
Group I, II and III among males and females. Males presented with group $I=25$ teeth, group $I I=42$ teeth, group $I I I=31$ teeth with $25.5 \%, 42.8 \%$ and $31.6 \%$ respectively. Female patients had distribution of tooth morphology as group I $=89$, group II were 80 and group III= 53 with $40.1 \%$, $36.1 \%$ and $23.8 \%$ respectively. $P$ value 0.067 is statistically not significant, thus difference of root morphology variation is not significant among genders.

Out of all 320 examined teeth, 114 teeth (35.6\%) were group I, 122 teeth (38.1\%) were group II, 84 teeth $(26.3 \%)$ were group III, while no tooth lied in group IV category. Thus two root morphology was most prevalent with group II + group III $(38.1+26.3 \%)=64.4 \%$, along with the fact that two root- fused form (group III) highest among all variations.

Bilateral root morphology was similar in 151 patients with exception in 9 patients. 3 male and 6 female patients showed morphology variation among right and left quadrant

Male patients showed group II in 20 patients bilaterally, group III in 15 patients bilaterally, group I in 11 patients bilaterally, while 3 patients had variation among right and left quadrant, with left side group I in all 3 patients and right side variation of group II in 2 patients and group III in 1 patient.

111 total females were studied with 222 teeth in both quadrants, gross morphology was same bilaterally except of 6 patients which presented with right side group II and left side group III in 2 patients, right side group I and left side group II in 3 patients and 1 patient presented with right side group III with left side group II root morphology.

\begin{tabular}{|l|c|}
\hline \multicolumn{1}{|c|}{ Age } & Mean (SD) \\
& $17.3(3.71)$ \\
\hline Gender & $\mathbf{N}(\%)$ \\
Female & $111(69.4)$ \\
Male & $49(30.6)$ \\
\hline
\end{tabular}

Table-I. Socio demographic characteristics.

\begin{tabular}{|l|c|c|}
\hline & Frequency & Percent \\
\hline group I & 57 & 35.6 \\
\hline group II & 61 & 38.1 \\
\hline group III & 42 & 26.3 \\
\hline Total & 160 & 100.0 \\
\hline
\end{tabular}

Table-II. Right quadrant root morphology.

\begin{tabular}{|l|c|c|}
\hline & Frequency & Percent \\
\hline group I & 57 & 35.6 \\
\hline group II & 62 & 38.8 \\
\hline group III & 41 & 25.6 \\
\hline Total & 160 & 100.0 \\
\hline
\end{tabular}

Table-III. Left quadrant root morphology.

\begin{tabular}{|c|c|c|c|}
\hline Classification of Roots & Female & Male & Total \\
\hline Single root (Group I) & 89 teeth $(40.1 \%)$ & 25 teeth $(25.5 \%)$ & $114(35.6 \%)$ \\
\hline Two roots -fused(Group II) & 80 teeth $(36.1 \%)$ & 42 teeth $(42.8 \%)$ & $122(38.1 \%)$ \\
\hline Two roots -separate(Group III) & 53 teeth $(23.8 \%)$ & 31 teeth $(31.6 \%)$ & $84(26.3 \%)$ \\
\hline$P$ value & \multicolumn{2}{|c|}{0.067} & $320(100 \%)$ \\
\hline
\end{tabular}

Table-IV. Percentage of roots in the first maxillary premolar by Gender.

\begin{tabular}{|c|c|c|c|c|c|}
\hline Author (year) & Country & No. of Teeth & One Root \% & Two Roots \% & Three Roots \% \\
\hline Lipski et al. (2005) ${ }^{12}$ & Poland & 142 & $15.5 \%$ & $75.3 \%$ & $9.2 \%$ \\
\hline Loh $(1998)^{5}$ & Singapore & 957 & $49.4 \%$ & $50.6 \%$ & $0 \%$ \\
\hline Chaparro et al. (1999) ${ }^{15}$ & Spain & 150 & $40.0 \%$ & $56.7 \%$ & $3.3 \%$ \\
\hline Awawdeh et al. (2008) ${ }^{7}$ & Jordan & 600 & $30.8 \%$ & $68.4 \%$ & $0.8 \%$ \\
\hline Atieh $(2008)^{6}$ & Saudi Arabia & 246 & $17.9 \%$ & $80.9 \%$ & $1.2 \%$ \\
\hline Ozcan et al. (2012) ${ }^{14}$ & Turkey & 653 & $45.2 \%$ & $53.7 \%$ & $1.1 \%$ \\
\hline Senan, Elham M., et al. (2018) ${ }^{11}$ & Yemen & 250 & $54.8 \%$ & $44.4 \%$ & $0.8 \%$ \\
\hline Tian $Y Y$ et al $(2012)^{3}$ & China & 300 & $66 \%$ & $33 \%$ & $1 \%$ \\
\hline Kafle Dashrhat; et al. (2015) ${ }^{4}$ & Neepal & 100 & $58 \%$ & $41 \%$ & $1 \%$ \\
\hline Present study & Pakistan & 320 & $35.6 \%$ & $64.4 \%$ & 0 \\
\hline
\end{tabular}

Table-V. Variation of Maxillary $1^{\text {st }}$ Premolar root morphology among various populations worldwide. 


\section{DISCUSSION}

Various populations when studied for gross root morphology of maxillary premolar teeth showed wide variation among maxillary $1^{\text {st }}$ premolar teeth ${ }^{11,12}$, but $2^{\text {nd }}$ premolar teeth has consistent morphology in most populations. Table-V explains variation of maxillary $1^{\text {st }}$ premolar root morphology among various populations worldwide. In our study, maxillary $1^{\text {st }}$ premolar teeth were studied only. This study revealed that two root form is more prevalent than single root form, along with the fact that fused root morphology is even more prevalent, this fact is similar with population of Jordan where $68.4 \%$ population has two roots out of this $63.2 \%$ have fused while $5.2 \%$ has bifurcated root morphology, on the other hand $73.3 \%$ of Uganda ${ }^{13}$ population has two root form in maxillary $1^{\text {st }}$ premolar tooth with only $16.9 \%$ are fused roots and remaining is bifurcated root morphology. Poland, Saudi Arabia, Kosovo, Turkish $^{14}$ and Spain ${ }^{15}$ also has population with prevalence of two root form. Three roots were not observed in any of patient in this study which is similar to Uganda and Singaporean population. Three roots are evident among various other populations but in a very less proportion, thus its clinical significance should always be considered as a rare possibility.

X Liu et al in 2019 studied Chinese population and revealed single root in $\max 1^{\text {st }}$ premolar as high as $72.2 \%$, whereas Tian $Y Y$ et al in 2012 revealed $66 \%$ prevalence of single root morphology, these results show variation from other Asian populations like Saudi Arabia, Pakistan, Singapore, Jordan and Turkey, where two root forms are more prevalent. Yemeni and Nepalese also have single root morphology more prevalent, same as Chinese population. These result shows a wide variation of root morphology of this tooth across the continents as well among Asian population.

H.S Loh in 1998 studied 957 maxillary $1^{\text {st }}$ premolars, among Singaporean population, results revealed two roots with fused morphology as high as $32.1 \%$, results are close to Pakistani population as $38.2 \%$, in his study two roots were as high as $50.6 \%$ and single root morphology was found in $49.4 \%$ patients.
Maxillary $1^{\text {st }}$ premolar is considered as a difficult tooth in terms of endodontic treatment also, due to its variation in number of roots, canal configuration, the direction and longitudinal depressions of the roots, and various pulp cavity configurations. Its gross root morphology is important to be understood along with prevalence of various root forms for oral surgeons, because it is most common tooth be extracted in orthodontic treatment plan, and atraumatic tooth extraction is almost always required in orthodontic extractions.

In our department of oral \& maxillofacial surgery all the orthodontic extraction teeth were delivered atraumatically via extraction forceps, only 4 teeth had broken roots during extraction, all these 4 teeth had two roots which were bifurcated, thin and flared thus bifurcated root form caries risk of broken roots during extraction, patients were informed about broken tooth root, 1 tooth root was left in situ with consultation and informed consent of patient and orthodontic department, due to the reason of close proximity to maxillary sinus and smaller size of root remnant, above mentioned decision was made, other 3 tooth roots were removed surgically via removing inter radicular bone only, thus buccal and palatal cortices were remained intact.

There are no possible limitations in this study, although other studies used various tools to study root and canal morphology like plain radiographs, use of CBCT along with clinical examination of gross root morphology ${ }^{15}$, but rationale of this study was to observe gross root morphology for orthodontic extraction purpose only, thus clinical examination was enough to gather required information.

\section{CONCLUSION}

There is increased propensity of two roots with fused root morphology in Pakistani population. Root morphology of maxillary $1^{\text {st }}$ premolar tooth shows wide variation among various ethnicities.

Copyright $@ 25$ Jan, 2021. 


\section{REFERENCES}

1. Araujo MT, Caldas DL. Tooth extractions in orthodontics: First or second premolars? Dental Press J. Orthod. 2019 Aug; 24(3):88-98. DOI: 10.1590/21776709.24.3.088-098.bbo.

2. Liu X, Gao M, Ruan J, Lu Q. Root canal anatomy of maxillary first premolar by microscopic computed tomography in a Chinese adolescent subpopulation. Bio Med. Res. Int. 2019 Nov 16; 2019. DOI: $10.1155 / 2019 / 4327046$.

3. Tian YY, Guo B, Zhang R, et al. Root and canal morphology of maxillary first premolars in a Chinese subpopulation evaluated using cone-beam computed tomography. Int endodont j. 2012 Nov; 45(11):9961003. DOI: 10.1111/j.1365-2591.2012.02059.x.

4. Dashrath K, Nisha A, Subodh S. Root morphology and tooth length of maxillary first premolar in Nepalese population. Dent. 2015; 5(8):2161-1122 DOI: $10.4103 / 0972-0707.71648$.

5. Loh HS. Root morphology of the maxillary first premolar in Singaporeans. Aust Dent J. 1998 Dec; 43 (6):399-402. doi: 10.1111/j.1834-7819.1998.tb00199.x.

6. Atieh MA. Root and canal morphology of maxillary first premolars in a Saudi population. $J$ Contemp Dent Pract. 2008 Jan 1; 9(1):46-53.

7. Awawdeh L, Abdullah H, Al-Qudah A. Root form and canal morphology of Jordanian maxillary first premolars. J. Endod. 2008 Aug 1; 34(8):956-61. DOI: 10.1016/j.joen.2008.04.013.

8. Patel HS, Managutti AM, Menat S, Agarwal A, Shah D, Patel J. Comparative evaluation of efficacy of physics forceps versus conventional forceps in orthodontic extractions: A prospective randomized split mouth study. J. Clin.Diagn.Res: JCDR. 2016 Jul; 10(7):ZC41. doi: 10.7860/JCDR/2016/17724.8160.
9. Dym $\mathrm{H}$, Weiss $\mathrm{A}$. Exodontia: tips and techniques for better outcomes. Dent Clin North Am. 2012 Jan; 56(1):245-66 doi: 10.1016/j.cden.2011.07.002.

10. Kapila S, Kaur T, Bhullar RS, Sandhu A, Dhawan A, Kaur A. Use of physics forceps in atraumatic orthodontic extractions of bilateral premolars: A randomized control clinical study. J Maxillofac Oral Surg. 2020 Sep; 19(3):347-354. DOI: 10.1007/s12663-020-01347-6.

11. Senan EM, Madfa AA, Alhadainy HA. Root and canal configuration of mandibular first molars in a Yemeni population: A cone-beam computed tomography. Eur Endod J. 2020; 5(1):10-17 doi: 10.14744/ eej.2020.99609.

12. Lipski M, Wozniak K, Lagocka R, Tomasik M. Root and canal morphology of the first human maxillary premolar. Durham Anthropol J. 2005; 12:2-3. doi: 10.4103/0972-0707.157260.

13. Rwenyonyi CM, Kutesa A, Muwazi L, Buwembo W. Root and canal morphology of maxillary first premolar teeth in a Ugandan population. Open J. Stomatol. 2011 Mar 22; 1(01):7-11. doi: 10.1007/s10266-0090100-0.

14. Özcan E, Çolak H, Hamidi MM. Root and canal morphology of maxillary first premolars in a Turkish population. J. Dent. Sci. 2012 Dec 1; 7(4):390-4. https:// doi.org/10.1016/j.jds.2012.09.003.

15. Chaparro AJ, Segura JJ, Guerrero E, Jimenez-Rubio $A$, Murillo $C$, Feito JJ. Number of roots and canals in maxillary first premolars: Study of an Andalusian population. Dent Traumatol. 1999 Apr; 15 (2):65-7. :https //doi.org/10.1111/j.1600-9657.1999.tb00755.x.

\begin{tabular}{|c|l|l|l|}
\hline \multicolumn{3}{|c}{ AUTHORSHIP AND CONTRIBUTION DECLARATION } \\
\hline Sr. \# & \multicolumn{1}{|c|}{ Author(s) Full Name } & Contribution to the paper & Author(s) Signature \\
\hline 1 & Maimoona Siddiq & Author & Author \\
2 & Junaid Shakeel & Author & \\
3 & Bushra Naeem Khan & Author \\
4 & Syed Zuhair Mehdi & Author + Data collection. \\
\hline 5 & Shoaib Hameed & Author \\
\hline 6 & Farooq Ahmad Chaudhary & \\
\hline
\end{tabular}

